\title{
ANESTHETIC MANAGEMENT OF A PATIENT WITH SITUS INVERSUS POSTED FOR LAPAROSCOPIC CHOLECYSTECTOMY
}

\author{
Sudhir Rao' ${ }^{1}$ Chaitanya 2 , Sahajananda 3 , Soumya Rohit ${ }^{4}$
}

\section{HOW TO CITE THIS ARTICLE:}

Sudhir Rao, Chaitanya, Sahajananda, Soumya Rohit. "Anesthetic Management of a Patient with Situs Inversus Posted for Laparoscopic Cholecystectomy". Journal of Evolution of Medical and Dental Sciences 2014; Vol. 3, Issue 14, April 07; Page: 3731-3736, DOI: 10.14260/jemds/2014/2352

ABSTRACT: Situs inversus totalis is a congenital visceral malrotation anomaly that results from disturbances in establishment of left-right asymmetry and it is characterized by total transposition of thoracic and abdominal viscera, and the predicted incidence is one in 10, 000 among the general population. In a patient with situs inversus totalis, not just the diagnosis of any acute abdomen pathology is difficult but equally challenging is the anesthetic management during the respective surgical procedure. We are reporting a patient who had situs inversus totalis and was operated for laparoscopic cholecystectomy under general anesthesia with I-gel, a new supraglottic airway device as an airway conduit. Though the problems related to such patients are mainly of surgical feasibility, an anesthesiologist must be aware of the associated problems of both, situs inversus and the laparoscopy. The present case report lays an emphasis on the potential difficulties during anesthetic management and its various implications. To the best of our knowledge, we report the first case in India of a successful laparoscopic cholecystectomy in a patient with situs inversus totalis with use of I-gel.

KEYWORDS: Cholecystectomy, Dextrocardia, I-gel, Situs inversus.

INTRODUCTION: The first case of situs inversus in humans was reported by Fabricius in $1600 .{ }^{1}$ This condition of abnormal visceral rotation was known in animals since the days of Aristotle. ${ }^{2}$ Situs inversus with dextrocardia is also termed situs inversus totalis because the thoracic as well as the abdominal viscera, is a mirror image of the normal anatomy. The incidence of situs inversus totalis has been thought to be 1:5000 to $1: 20000 .{ }^{2,3}$

During the embryological development, a 270-degree clockwise rotation instead of normal 270 degree anti-clockwise of the developing thoraco-abdominal organs results in mirror image positioning of the abdominal and thoracic viscera. ${ }^{4}$ This defect may present difficulties in the diagnosis and management of abdominal pathology due to mirror-image anatomy. The association of situs inversus totalis with syndromes such as Kartagener's syndrome, cardiac anomalies, spleen malformations and other such clinical entities makes the clinical scenario extremely challenging for the concerned anesthesiologist. ${ }^{5}$

We are reporting a case of situs inversus totalis who underwent laparoscopic cholecystectomy, under general anesthesia with I-gel as an airway conduit. The anesthetic considerations and implications associated with such anatomical abnormalities are discussed.

CASE REPORT: A 25 year old male, weighing $35 \mathrm{~kg}$, presented with pain in abdomen for the last 3 days. He was mentally retarded and had tremors since childhood. There was no history suggestive of repeated respiratory tract infections like bronchiectasis and pan sinusitis. Ultrasonography abdomen for the evaluation of pain revealed situs inversus and X-ray chest revealed dextrocardia with fundic 
gas shadow on right side [Figure 1]. Computed tomography (CT) thorax and abdomen revealed situs inversus totalis. Echocardiograph revealed normal cardiac parameters with ejection fraction of $62 \%$ and dextrocardia. On examination, he had bilateral hand tremors. Airway examination revealed Mallampatti class II. Hemodynamic parameters were within normal limits. He was scheduled to undergo laparoscopic cholecystectomy.

In the preanesthetic room intravenous access was secured. Inj Pantoprazole $20 \mathrm{mg}$ and inj. Ondansetron $6 \mathrm{mg}$ were given intravenously. In the operation room, ECG (leads, mirror image of normal), NIBP and pulse oximeter were connected. Premedicated with inj. Midazolam $1 \mathrm{mg}$ and inj. Fentanyl 80 mcg.

Patient was induced with inj. Propofol $100 \mathrm{mg}$ and 2\% Sevoflurane. Neuromuscular blockade was achieved with inj. Vecuronium $6 \mathrm{mg}$. Cuff less supraglottic airway device I-gel was inserted, placement confirmed with bilateral air entry on auscultation and $\mathrm{ETCO}_{2}$ wave form. I-gel was fixed and controlled ventilation was instituted with ventilator settings of tidal volume- $12 \mathrm{ml} / \mathrm{kg}$, Respiratory rate-12/min and I: E = 1:2. Ryle's tube No. 12 was passed through I-gel [Figure 2].

During laparoscopic surgery orientation and ergonomics were altered, surgeon stood on right side and video monitor was shifted to left side of patient. Total operating time was 95 min.

Anesthesia was maintained with $\mathrm{O}_{2}: \mathrm{N}_{2} \mathrm{O}=60: 40$, isoflurane $0.6-1 \%$ and intermittent doses of inj. Vecuronium. $\mathrm{SpO}_{2}$ was ranging between 98-99\%. $\mathrm{ETCO}_{2}$ was ranging between 28-36 mmHg. At the end of surgery, when the patient had respiratory attempts, residual neuromuscular blockade was reversed with Inj. Neostigmine $2.5 \mathrm{mg}$. and inj.

Glycopyrolate $0.4 \mathrm{mg}$. After Ryle's tube and oral suctioning, I-gel was removed and patient was shifted to recovery room. Perioperative period was uneventful and patient was discharged from hospital on fifth post-operative day.

DISCUSSION: Situs inversus totalis is a rare congenital disorder occurring in $0.01 \%$ of the population6.This entity is considered to have a genetic predisposition that is autosomal recessive with the defect being localized on the long arm of chromosome $14 .{ }^{7}$

It is characterized by the transposition of the major thoracic organs and all the visceral organs of the abdomen to the side opposite to normal position in the body. The liver and gall bladder are located on the left, while the stomach and the spleen are on the right. The normal development requires a 270 degree counterclockwise rotation that yields the normal anatomy. In situs inversus totalis, the 270 degree rotation is in the clockwise direction. ${ }^{4}$

Early embryonic process of determination of normal body situs is complex and probably controlled by several genes. ${ }^{8}$ The exact etiology is unclear; however, it is thought to be due to a single autosomal recessive gene of incomplete penetration. The male to female ratio is $1: 1$ and there is no racial predilection. 9,10

In acute abdomen, it is important to be aware of the presence of situs inversus to ensure the correct diagnosis and treatment. Acute appendicitis causes left lower quadrant pain, whereas cholecystitis causes left upper quadrant pain in these patients. CT scanning is the preferred diagnostic modality as it shows the anatomical details.

In this case the patient presented with right upper quadrant pain only and had no definite left upper quadrant pain. It has been noted in $30 \%$ of previous reported cases of acute cholecystitis in patients with situs inversus that the pain was felt in the epigastrium alone and in $10 \%$ the pain was 
localized to the right upper quadrant. ${ }^{11}$ The proposed explanation for this is that the central nervous system may not share in the general transposition.

Patients with situs inversus who are scheduled for laparoscopic cholecystectomy should be assessed pre-operatively for any potentially serious cardiac or respiratory abnormalities.

While there is no evidence to suggest that there is an increased risk of bile duct injuries in patients with situs inversus, the orientation and ergonomic challenges may result in an increased operative time. ${ }^{12}$ The procedure becomes difficult because of the fact that the anatomy is mirror image of that of routinely seen and most surgeons are right handed.

A case of prolonged paralysis after administration of succinylcholine has been reported earlier in a patient with situs inversus totalis. ${ }^{13}$ However we avoided succinylcholine since there was no anticipation of difficult airway. Use of I-gel, which is a cuff less supraglottic airway device with a gastric channel, is well accepted during laparoscopic surgeries. ${ }^{14}$

I-gel has advantages like easier insertion, minimal risk of tissue compression, stability after insertion and smooth awakening. It produces lower hemodynamic instability during placement and avoids stimulating the infraglottic structures. High leak pressure and low peak pressure ensure safe ventilation and decreased the risk of gastric insufflations, even in obese patients (body mass index $>35 \mathrm{~kg} / \mathrm{m}$ ) who were ventilated with $22 \mathrm{~cm} \mathrm{H}_{2} \mathrm{O}$ peak pressure.

An integrated gastric channel facilitates venting of gas from the stomach and allows for the passing of a nasogastric tube to empty the stomach contents. The positive pressure should be kept below $40 \mathrm{~cm}$ of $\mathrm{H}_{2} \mathrm{O}$ during intermittent positive pressure ventilation and in our case it did not cross $26 \mathrm{~cm}$ of $\mathrm{H}_{2} \mathrm{O}$. Though mucociliary dysfunction leading to increased secretions may be associated with situs inversus, there were no signs and symptoms suggestive of increased mucoserous secretions (history of repeated sinusitis, bronchiectasis) in our case. Hence use of a supraglottic device is justified and there is less stimulation of infraglottic structures which itself can lead to increased secretions and bronchospasm.

In situs inversus, special considerations are:

a. ECG electrodes and defibrillator pads are placed reverse.

b. The association of situs inversus with other syndromes and diseases such as Kartagener's syndrome, mucociliary dysfunction, airway anomalies, etc., which may predispose the patient to numerous varieties of airway difficulties and pulmonary infections that can have considerable implications during induction of anesthesia and intubation

c. The syndrome is associated with numerous cardiac anomalies such as atrial septal defects, ventricular septal defects, transposition of great vessels, absent coronary sinus, double-outlet right ventricle, total pulmonary anomalous venous defect and pulmonary valve stenosis either singly or in combination ${ }^{15}$.

d. In case of inversion of great vessels preference, should be given to left internal jugular vein for cannulation (to avoid thoracic duct and to ensure direct access to right atrium).

e. Main stem intubation occurs often to the left ${ }^{16}$.

f. The spinal deformities like split cord, spina bifida, meningomyelocele, scoliosis, etc. have been described in the literature, and one has to evaluate the patient carefully if any surgery is planned under neuraxial anesthesia. 
g. In thoracic surgery the anatomy of the bronchi should be considered before selecting a double lumen tube. Insertion of a double-lumen tube will pose a multitude of challenges, and the successful intubation and separation of lungs cannot be accomplished without the aid of fibreoptic bronchoscope. The transposition of the thoracic viscera also alters the various anatomical landmarks, and one has to be well acquainted with ultrasound-guided procedures if in case a need arises for invasive central venous cannulation and brachial plexus blockade.

h. Uterine displacement in a parturient is logically to the right in these patients ${ }^{15}$.

i. Situs inversus in Kartagener's syndrome is invariably associated with mucociliary dysfunction.

Primary ciliary dyskinesia is present in $25 \%$ of the patients with situs inversus totalis with an increased probability of developing respiratory complications. Therefore, moist and filtered mixture of gases should be administered during mechanical ventilation. The role of bronchodilators, chest physiotherapy, postural drainage, antibiotics and incentive spirometry cannot be underestimated and is mandatory in optimizing the pulmonary status before any surgical procedure.

CONCLUSION: To conclude with meticulous planning and care, patients with Situs inversus can be successfully managed. A Supraglottic device is a good option if situs inversus is not associated with Kartagener's syndrome.

\section{REFERENCES:}

1. Pitiakoudis M, Tsaroucha AK, Katotomichelakis M, Polychronidis A, Simopoulos C. Laparoscopic cholecystectomy in a patient with situs inversus using ultrasonically activated coagulating scissors. Report of a case and review of the literature. Acta Chir Belg. 2005; 105:114-7.

2. McKay D, Blake G. Laparoscopic cholecystectomy in situs inversus totalis: A case report. BMC Surg. 2005; 5:5.

3. Kumar S, Fusai G. Laparoscopic cholecystectomy in situs inversus totalis with left-sided gall bladder. Ann R Coll Surg Engl. 2007; 89:W16-8.]

4. Song JY, Rana N, Rottman CA. Laparoscopic appendicectomy in a female patient with situs inversus: Case report and literature review. JSLS 2004; 8:175-7.

5. Mathew PJ, Sadera GS, Sharafuddin S, Pandit B. Anaesthetic considerations in Kartagener's syndrome: A case report. Acta Anaesthesiol Scand 2004; 48:518-20.

6. Moreli SH, Young L, Reid B, Ruttenberg H, Bamshad MJ. Clinical analysis of families with heart, midline and laterality defects. Am J Med Genet. 2001; 101:388-92.

7. Franklin ME, Jr, Almeida JA, Pérez ER, Robert LP, Majarrez A. Cholecystectomy and appendectomy by laparoscopy in a patient with situs inversus totalis. A case report and review of the literature. Asoc Mex Cir Endoscopica. 2001; 2:150-3.

8. Carmi R, Roughman J, Rosenbaum K: Human situs determination is probably controlled by several different genes. Am J Med Genet 44:246-247, 1992.

9. Casey B. Genetics of human situs abnormalities. Am J Med Genet 2001; 101:356-8.

10. Nawaz A, Matta H, Hamchou M, Jacobez A, Trad O, Al Salem AH. Situs inversus abdominus in association with congenital duodenal obstruction: A report of two cases and review of the literature. Pediatr Surg Int 2005; 21:589-92. 
11. Rao PG, Katariya RN, Sood S, Rao PLNG: Situs inversus totalis with calculus cholecystitis and mucinous cystadenomas of ovaries. J Postgrad Med 1977, 23:89-90.

12. Yaghan RJ, Gharaibeh KI, Hammori S. Feasibility of laparoscopic cholecystectomy in situs inversus. J Laparoendosc Adv Surg Tech. 2001; 11:233-7.

13. Nayak R, Meck J, Hannallah M. Atypical cholinesterase in a patient with situs inversus totalis. Anesthesiology 1995;83:881

14. Natalini G, Lanza G, Rosano A, Dell'Agnolo P, Bernardini A. Standard laryngeal mask airway and LMA-ProSeal during laparoscopic surgery. J Clin Anesth 2003; 15:428-32.

15. Winer-Muram HT. Adult presentation of heterotaxic syndromes and related complexes. J Thorac Imaging 1995; 10:43-57.

16. Franklyn P. Cladis. Index of Syndromes and their Paediatric Anaesthetic Implications. Etsuro K. Motoyoma, Peter J.Davis. Smith's Anaesthesia for Infants and Children Philadelphia 2006: 1219.

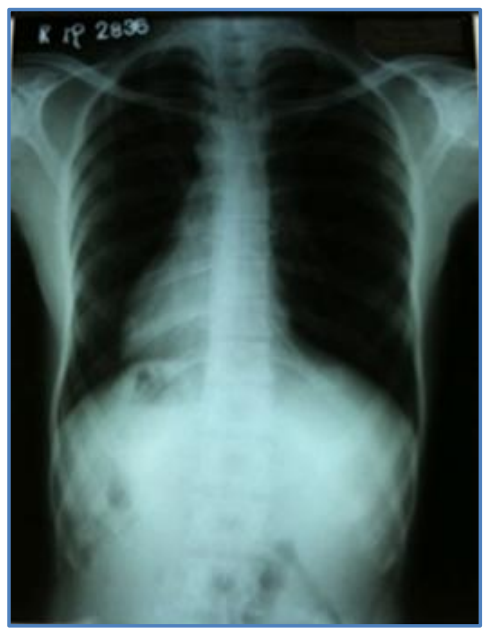

Figure 1: X-ray chest showing dextrocardia with fundic gas shadow on right side

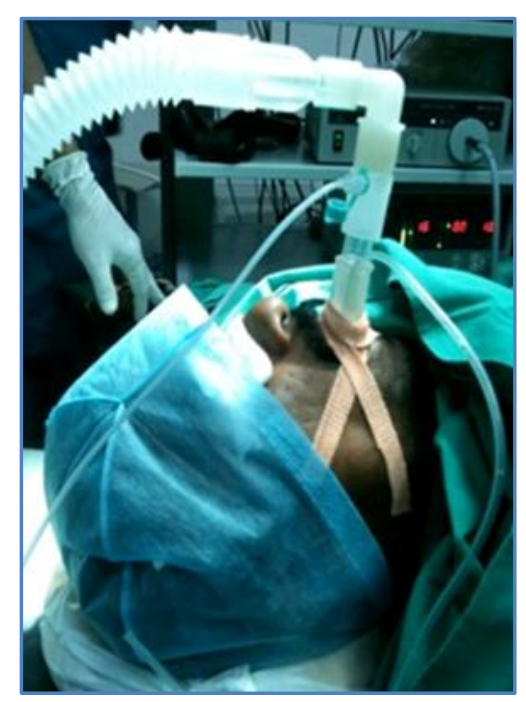

Figure 2: I-gel with Ryle's tube in situ 


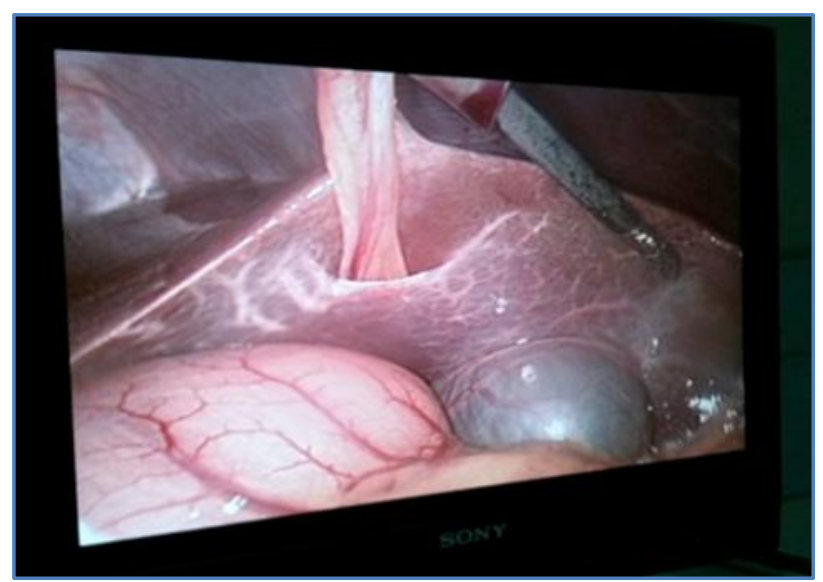

Figure 3: Laparoscopic cholecystectomy in Progress

\section{AUTHORS:}

1. Sudhir Rao

2. Chaitanya

3. Sahajananda

4. Soumya Rohit

\section{PARTICULARS OF CONTRIBUTORS:}

1. Post Graduate, Department of Anaesthesiology, Rajarajeswari Medical College and Hospital, Bangalore.

2. Assistant Professor, Department of Anaesthesiology, Rajarajeswari Medical College and Hospital, Bangalore.

3. Professor and HOD, Department of Anaesthesiology, Rajarajeswari Medical College and Hospital, Bangalore.
4. Assistant Professor, Department of Anaesthesiology, Rajarajeswari Medical College and Hospital, Bangalore.

\section{NAME ADDRESS EMAIL ID OF THE CORRESPONDING AUTHOR:}

Dr. H. Sahajananda,

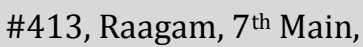
Vijaya Bank Colony, Bannerghatta Road, Bangalore - 76.

E-mail: sahaj_anand@hotmail.com

Date of Submission: 26/02/2014. Date of Peer Review: 27/02/2014. Date of Acceptance: 19/03/2014. Date of Publishing: 05/04/2014. 